\title{
A NEW POTATO LATE BLIGHT DISEASE PREDICTION MODEL AND ITS COMPARISON WITH TWO PREVIOUS MODELS
}

\author{
W.R.HENSHALL ${ }^{1}$, D. SHTIENBERG ${ }^{2}$ and R.M.BERESFORD ${ }^{1}$ \\ ${ }^{1}$ HortResearch, Mt Albert Research Centre, PB 92169, Auckland, New Zealand \\ ${ }^{2}$ Agricultural Research Organization, The Volcani Centre, PO Box 6, \\ Bet Dagan, Israel \\ Corresponding author: whenshall@hortresearch.co.nz
}

\begin{abstract}
There are numerous disease prediction models for potato late blight based on recognition of weather conditions suitable for infection. The models have the potential to target fungicide application to times of greatest need, with a consequent reduction in chemical use. The Hartill-Young late blight model was developed about 20 years ago from disease and weather data recorded at the Pukekohe Research Station. This paper presents the more sophisticated Shtienberg model, which was developed recently from the same data but which treats components of the disease process separately. The outputs of the Hartill-Young and Shtienberg models and the established Fry model were analysed for the same input weather data, at Pukekohe (high disease risk area) and Lincoln (low risk) over the last five growing seasons. The Shtienberg model gave broadly similar results to the other two models.
\end{abstract}

Keywords: potato late blight, disease prediction model, disease forecasting.

\section{INTRODUCTION}

Current management of potato late blight (Phytophthora infestans) in the high rainfall Pukekohe area (Franklin District, North Island, New Zealand) is by regular application of fungicides. There is potential to use weather-based disease management systems (DMS) to reduce the typically high number of fungicide applications. Possible ways of using DMS in this environment are through delaying a scheduled spray if conditions are unsuitable for late blight development, or through changing the chemical product according to perceived risk. The heart of such a DMS is a model incorporating aspects of the potato late blight life cycle and the effects of temperature and some measure of wetness on disease development. Such models may also be used to evaluate biosecurity risk associated with the arrival in New Zealand of more virulent strains of the pathogen.

Previously three potato late blight infection models have been compared using weather data from Pukekohe and Lincoln (Canterbury, South Island, New Zealand) (Henshall \& Beresford 2004). The models were the Smith model developed in the UK (Smith 1956), the Fry model developed in the USA (Fry et al. 1983), and the Hartill-Young model developed locally (Hartill \& Young 1985). The study showed that the Smith model was able to discriminate between more favourable and less favourable infection conditions, but at Pukekohe the other two models generated near continuous indication of risk. However, after modification to reduce sensitivity, the Fry and Hartill-Young models were also able to discriminate between more favourable and less favourable infection conditions. These two models use hourly weather data, so have the potential to process more information than is possible using the Smith model that is based on daily readings.

In this paper a new model, referred to here as the Shtienberg model, is described and compared with the Fry and Hartill-Young models, modified as in Henshall \& Beresford (2004), to illustrate patterns of predicted disease risk across multiple sites and seasons. 
The Shtienberg model uses hourly weather data and incorporates public domain information on potato late blight sporulation and infection processes.

\section{METHODS}

Infection periods (IPs) were calculated for each model from hourly temperature, relative humidity (RH) and surface wetness data obtained from HortResearch field weather stations at Pukekohe and Lincoln. The Fry model, expressed as blight units, is based on temperature and number of hours of high $\mathrm{RH}$, according to a table that takes into account cultivar susceptibility. The criteria for a moderately susceptible cultivar were used. For the Hartill-Young model, if the output of an artificial leaf wetness sensor was above a $50 \%$ threshold, hourly temperature $>7.2^{\circ} \mathrm{C}$ is summed. A sum of 80 degree hours is one IP; IPs can follow successively under warm wet conditions. A 2 hour gap in wetness is permitted under conditions of intermittent wetting and drying.

\section{Shtienberg model}

The dataset used by Hartill \& Young (1985) from 1981-1983 was reanalysed to derive new meteorological criteria for late blight risk. The dataset consisted of late blight records on potted potato plants that were exposed for 2-3 day periods in experimental potato crops in which late blight epidemics were allowed to develop. There were simultaneous records of airborne spores and hourly in-crop temperature, relative humidity, surface wetness and rainfall.

The Shtienberg model has separate criteria (0-4 scale) for sporulation, spore dispersal, spore survival and infection potential. A key component in the calculation of the sporulation and infection potential indices is wetness duration, based on the number of hours the output of a wetness sensor exceeds a threshold. This threshold is different for each index. Conversely the spore dispersal and spore survival indices depend on dryness duration, based on the number of hours the wetness sensor output is zero.

Each day (D) risk is assessed at $11 \mathrm{am}$. The sporulation index depends on number of hours wet and mean air temperature over the $24 \mathrm{~h}$ ending at $5 \mathrm{pm}$ on D-1 (Table 1). An hour is considered wet if the wetness sensor reads $\geq 10 \%$ of its maximum. The spore dispersal index decreases the value of the sporulation index according to the number of hours of dryness in the $24 \mathrm{~h}$ from 1 am to midnight on D-1. An hour is considered dry if the wetness sensor reads zero. The spore survival index decreases the value of the sporulation index used for the previous risk assessment (calculated from $6 \mathrm{pm} \mathrm{D}-3$ to $5 \mathrm{pm} \mathrm{D}-2$ ) if there are more than $7 \mathrm{~h}$ dryness over the $24 \mathrm{~h}$ from $1 \mathrm{am}$ to midnight on D-2 (Tables $2 \& 3$ ). The inoculum index for the day of risk assessment is a combination of the spore dispersal and spore survival indices (Table 4). The infection potential index for the day of risk assessment is calculated from number of hours wet and mean temperature over the $24 \mathrm{~h}$ ending at $11 \mathrm{am}$ on the current day D (Table 5). An hour is considered wet if the sensor reads $\geq 75 \%$ of its maximum. The final step is to combine the inoculum index with the infection index to produce a late blight risk index (0-3) corresponding to nil, light, moderate and severe risk (Table 6).

\section{Model comparison}

To reduce the sensitivity of the Hartill-Young and Fry models and to simplify the output for comparison purposes, model outputs were modified as in Henshall \& Beresford (2004). The first IP (if any) per day of the Hartill-Young model output was ignored. Fry blight units were simplified by ignoring the first five units per day. The result was a sequence of days representing presence or absence of risk according to these criteria. The modified sequences of daily Hartill-Young IPs and Fry blight units were then compared with the sequence of severe Shtienberg IPs over the five seasons 2001/02 to 2005/06.

\section{RESULTS}

The Shtienberg model generated more IPs than the two established models. The relative frequency of IPs detected by the three models, after modification to reduce sensitivity, for the five seasons and two sites was in the order Shtienberg $>$ Fry $>$ Hartill-Young (Fig. 1). There were fewer days with IPs at Lincoln than at Pukekohe. 
TABLE 1: Sporulation index as a function of temperature $\left({ }^{\circ} \mathrm{C}\right)$ and wetness duration for the $24 \mathrm{~h}$ ending $5 \mathrm{pm} \mathrm{D}-1$. An hour is considered wet if the sensor reads $\geq 10 \%$ of its maximum.

\begin{tabular}{cccccc}
\hline & \multicolumn{5}{c}{ Mean temperature during Wet hours } \\
\cline { 2 - 6 } Hours Wet & $<7.0$ or & $7.0-8.5$ or & & & \\
\hline $0-2$ & $>25$ & $20.1-25$ & $8.6-12.0$ & $12.1-17.0$ & $17.1-20.0$ \\
$3-6$ & 0 & 0 & 1 & 1 & 0 \\
$7-11$ & 0 & 1 & 2 & 2 & 1 \\
$12-15$ & 0 & 2 & 3 & 4 & 2 \\
$\geq 16$ & 1 & 3 & 4 & 4 & 3 \\
\hline
\end{tabular}

TABLE 2: Spore dispersal index as a function of sporulation index and dryness duration for the $24 \mathrm{~h}$ ending midnight D-1. An hour is considered dry if the sensor reads zero.

\begin{tabular}{cccccc}
\hline & \multicolumn{5}{c}{ Hours Dry } \\
\cline { 2 - 6 } Sporulation index & $0-2$ & $3-6$ & $7-11$ & $12-15$ & $\geq 16$ \\
\hline 0 & 0 & 0 & 0 & 0 & 0 \\
1 & 1 & 1 & 1 & 1 & 1 \\
2 & 1 & 1 & 2 & 2 & 2 \\
3 & 1 & 1 & 2 & 3 & 3 \\
4 & 2 & 2 & 3 & 4 & 4 \\
\hline
\end{tabular}

TABLE 3: Spore survival index as a function of sporulation index for the $24 \mathrm{~h}$ ending $5 \mathrm{pm}$ D-2 and dryness duration for the $24 \mathrm{~h}$ ending midnight D-2. An hour is considered dry if the sensor reads zero.

\begin{tabular}{cccccc}
\hline & \multicolumn{5}{c}{ Hours Dry } \\
\cline { 2 - 6 } Sporulation index & $0-2$ & $3-6$ & $7-11$ & $12-15$ & $\geq 16$ \\
\hline 0 & 0 & 0 & 0 & 0 & 0 \\
1 & 1 & 1 & 0 & 0 & 0 \\
2 & 2 & 2 & 1 & 0 & 0 \\
3 & 3 & 3 & 2 & 1 & 0 \\
4 & 4 & 4 & 3 & 2 & 2 \\
\hline
\end{tabular}

TABLE 4: Inoculum index calculated by combining spore dispersal and spore survival indices.

\begin{tabular}{cccccc}
\hline & \multicolumn{5}{c}{ Spore survival index } \\
\cline { 2 - 6 } Spore dispersal index & 0 & 1 & 2 & 3 & 4 \\
\hline 0 & 0 & 1 & 2 & 3 & 4 \\
1 & 1 & 2 & 3 & 4 & 4 \\
2 & 2 & 3 & 4 & 4 & 4 \\
3 & 3 & 4 & 4 & 4 & 4 \\
4 & 4 & 4 & 4 & 4 & 4 \\
\hline
\end{tabular}


TABLE 5: Infection potential index as a function of temperature $\left({ }^{\circ} \mathrm{C}\right)$ and wetness duration for the $24 \mathrm{~h}$ ending 11 am on day $\mathrm{D}$. An hour is considered wet if the sensor reads $\geq 75 \%$ of its maximum.

\begin{tabular}{cccccc}
\hline \multirow{2}{*}{$\begin{array}{l}\text { Mean temperature } \\
\text { during Wet hours }\end{array}$} & $0-3$ & $4-6$ & $7-11$ & $12-16$ & $\geq 17$ \\
\cline { 2 - 6 } & 0 & 0 & 1 & 1 & 2 \\
$7-12$ & 0 & 1 & 2 & 2 & 3 \\
$12-15$ & 0 & 1 & 2 & 3 & 4 \\
$15-26$ & 1 & 2 & 3 & 3 & 4 \\
$26-29$ & 0 & 1 & 2 & 3 & 4 \\
$29-32$ & 0 & 1 & 2 & 2 & 3 \\
$>32$ & 0 & 0 & 1 & 1 & 2 \\
\hline
\end{tabular}

TABLE 6: Late blight risk index ( $0=$ nil, $3=$ high $)$ as a function of inoculum and infection potential indices.

\begin{tabular}{cccccc}
\hline & \multicolumn{5}{c}{ Infection potential index } \\
\cline { 2 - 6 } Inoculum index & 0 & 1 & 2 & 3 & 4 \\
\hline 0 & 0 & 0 & 0 & 0 & 1 \\
1 & 0 & 0 & 1 & 2 & 2 \\
2 & 0 & 1 & 2 & 2 & 3 \\
3 & 0 & 1 & 2 & 2 & 3 \\
4 & 0 & 1 & 3 & 3 & 3 \\
\hline
\end{tabular}

\section{DISCUSSION}

The numbers of IPs generated by the three models differed within each of the five years, and the pattern from year to year was not consistent. For example at Pukekohe, in 2001 and 2005 the numbers of days indicating severe infection events were similar for the Shtienberg and Fry models, whereas in the other three years the Shtienberg model generated severe events on at least twice as many days as the Fry model. A possible explanation for the difference between these two models is that the Shtienberg model allows for spore survival over 2 days, with the potential to spread a given infection event over several days. The lower frequency of IPs at Lincoln reflects the drier climate of Canterbury compared with South Auckland.

In general the results of the model comparisons are similar to those of Henshall \& Beresford (2004). The problem of over sensitivity had to be dealt with by considering only the most severe indications from the models, including the newly developed model. Again it must be emphasised that the field performance of the models has not been investigated in this study. Incorporating any model into a practical DMS is far from trivial, as illustrated by current research into the application of the LATEBLITE model developed 20 years ago (Andrade-Piedra et al. 2005). Even when a DMS has been fully developed, uptake by growers is not assured (Parker 1999).

There are conflicting requirements for any model that is to be incorporated into a DMS. It has to represent disease development as accurately as possible, but at the same time it has to distinguish between periods of greater disease risk and periods of lesser disease risk. The Shtienberg model has potential for inclusion in DMS because it was developed using local data, and includes more detail of disease processes than the Hartill-Young model. Its usefulness for timing fungicide applications needs to be tested in field trials. The Shtienberg model will be further developed and used to investigate the potential impact of new and more virulent strains of $P$. infestans that might arrive from overseas or develop within New Zealand. 

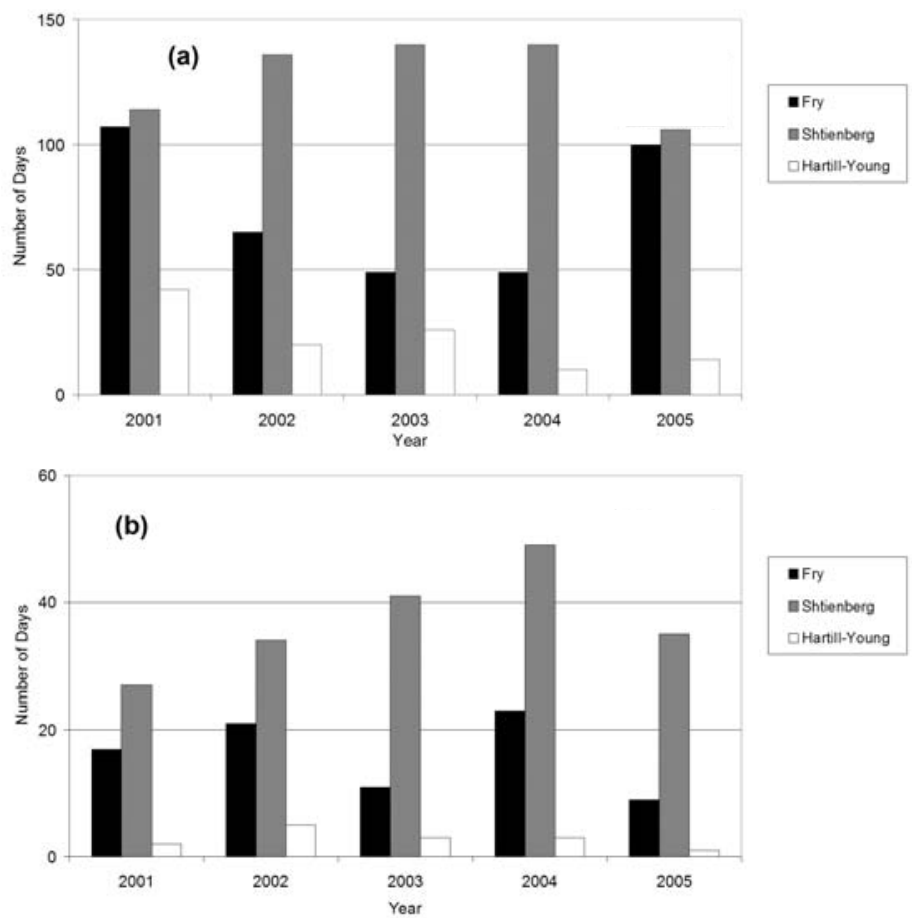

FIGURE 1: The number of days when potato late blight infection periods were predicted by the Fry, Shtienberg and Hartill-Young models at (a) Pukekohe and (b) Lincoln for the 7-month seasons commencing September 2001 through to September 2005. Model outputs have been modified to reduce sensitivity.

\section{ACKNOWLEDGEMENTS}

The New Zealand Foundation for Research, Science and Technology (Contract C10X0317) is acknowledged for funding the model comparison.

\section{REFERENCES}

Andrare-Piedra JL, Forbes GA, Shtienberg D, Grunwald NJ, Chacon MG, Taipe MV, Hijmans RJ, Fry WE 2005. Qualification of a plant disease simulation model: performance of the LATEBLIGHT model across a broad range of environments. Phytopathology 95: 1412-1422.

Fry WE, Apple AE, Bruhn JA 1983. Evaluation of potato late blight forecasts modified to incorporate host resistance and fungicide weathering. Phytopathology 73: 1054-1059.

Hartill WFT, Young K 1985. Recent New Zealand studies on the chemical control of late blight of potatoes. In: Hill GD, Wratt GS ed. Potato growing - a changing scene. Agronomy Society of New Zealand. Pp. 55-60.

Henshall WR Beresford RM 2004. Adaptation of potato late blight prediction models for New Zealand. New Zealand Plant Protection 57: 25-29.

Parker CG 1999. Decision support systems: lessons from past failures. Farm Management 10: 273-289. Smith LP 1956. Potato late blight forecasting by $90 \%$ humidity criteria. Plant Pathology 5: 83-87. 